\title{
The Effects of Group Sand play on the Psychological Health and Resilience of Street Children and Adolescents in Uganda ${ }^{*}$
}

\author{
Alice Kolawole Olaniyi" Shallon Atuheire ${ }^{* * *}$ Lesley Lally ${ }^{* * * *}$ Ruán Kane ${ }^{* * * * *}$ \\ Iryna Danilova ${ }^{* * *+* * *}$ Claudia Walker ${ }^{* * * * * * * *}$ Lynda Earls ${ }^{* * *+* a * * *}$ Eimíle Holton
}

\begin{abstract}
$<$ Abstract $>$
The authors analysed the effects of group Sandplay therapy on adolescents' psychological health and resilience in a mixed-method research. They explored and categorized the themes these adolescents expressed during therapy. Fifteen children $(n=15)$ were recruited for the study; (Boarding school children $=5$; Day school children $=5$; Street children $=5$ ). The selection process was conducted
\end{abstract}

* The Authors wish to show our sincere appreciation and gratefulness to Dr Ian McCabe, Clinical director, JIFACA for funding this research.

** Corresponding Author: Jungian Institute for Free Analysis for Children and Adolescents (JIFACA), Sunshine Industrial Estate Crumlin, Dublin, Ireland. JIFACA, Crumlin, Dublin, +353 868690643 (alice.olaniyi@gmail.com)

*** Jungian Institute for Free Analysis for Children and Adolescents (JIFACA), Sunshine Industrial Estate Crumlin, Dublin, Ireland. (satuheire@yahoo.com)

**** Jungian Institute for Free Analysis for Children and Adolescents (JIFACA), Sunshine Industrial Estate Crumlin, Dublin, Ireland. (llally0101@gmail.com)

***** Jungian Institute for Free Analysis for Children and Adolescents (JIFACA), Sunshine Industrial Estate Crumlin, Dublin, Ireland. (ruandanielkane@hotmail.com)

****** Jungian Institute for Free Analysis for Children and Adolescents (JIFACA), Sunshine Industrial Estate Crumlin, Dublin, Ireland. (pr.danilova@gmail.com

******* Jungian Institute for Free Analysis for Children and Adolescents (JIFACA), Sunshine Industrial Estate Crumlin, Dublin, Ireland. (claudrwalker@gmail.com)

******** Jungian Institute for Free Analysis for Children and Adolescents (JIFACA), Sunshine Industrial Estate Crumlin, Dublin, Ireland. (ynda.earls1@gmail.com

********* Jungian Institute for Free Analysis for Children and Adolescents (JIFACA), Sunshine Industrial Estate Crumlin, Dublin, Ireland. (eimileh@gmail.com) 
Journal of Symbols \& Sandplay Therapy, Vol.12 No.1.

in cooperation with an orphanage in Kabale, Uganda. The children who participated in the study underwent a forty-five-minute sand play therapy every week for nine weeks. The SDQ and RCADS were administered to the groups both pre- and post-intervention, with the data entered and analysed using SPSS. Group sandplay was found to significantly decrease the adolescents' internalizing problems such as anxiety and depression, while their resilience had also significantly improved. The narrative analysis, in turn, yielded seven themes: basic needs; community-love-celebration; giving help-leadership-empowerment; security-danger, recreation-self-development-self-nurturance, education, and seeking help-faith.

Keywords : group sandplay therapy, anxiety, depression, Resilience, Uganda, Orphanage, street children, Maslow's theory

Uganda has one of the world's youngest populations, with over 56 per cent of its 37 million citizens under 18 years of age (Human Rights Watch, 2014). The United Nations had estimated up to 150 million street children worldwide (Roncević, Stojadinović, \& Batrnek-Antonić, 2013). New Vision (2001) highlighted that 8000 children roam and sleep on the streets, with an estimated 4,000 in Kampala, 800 in Mbale, 500 in Jinja, and the remainder in other urban hubs. In Uganda, 38 per cent of the population achieves less than one euro per day (World Bank, 2013). Experiencing poverty causes a family's inability to meet their basic needs (food, shelter, medicine, education, clothes). In these instances, families often become reliant on the children for income. A National Labour Force and Child Activities Survey (2011/2012) estimates that 16 per cent of Ugandan children between the ages of five and seventeen experience child labour and exploitation (International Labour Organization, 2013). More alarming in the 2016/2017 version, 54.2 per cent of working children experienced child labour and exploitation.

Child labour is considered one factor that determines the influx of children wandering the streets (International Labour Organization, 2018) due to their struggles to flee poverty, exploitation and abusive situations. Other factors include many families' adverse circumstances in Uganda, including parental illness, disruption in families, physical abuse, sexual abuse, and death of parents. These experiences can often lead some children to leave home to find a better 
chance of survival on the streets (Embleton Lee, Gunn, Ayuku, \& Braitstein, 2016; Munene \& Nambi, 1996). Most stakeholders working with street children acknowledge that the street children's population is increasing, even though social care and governmental organisations have difficulty obtaining accurate numbers (UNESCO, 2017). Van Blerk (2003) illustrates a rapid increase of street children in expanding Kampala and other Sub-Saharan African cities due to increasing urbanisation, social-economic restructuring, and socioeconomic deterioration in many home environments (Van Blerk, 2003; Harper \& Marcus, 2000; Bayat, 2000). Once on the streets, these children are exposed to drug use, alcoholism, risk of kidnapping, petty theft, prostitution, and diseases such as malaria, dysentery and sexually transmitted infections (Garg, 2004). The superstitious thinking of some adults can be a detriment to children's welfare, the belief in sacrificing humans to gods, where children can become prey to these circumstances are examples of children becoming vulnerable, unsafe, unprotected, unloved when on the street.

According to Findings from a National Survey (UNICEF, 2015), 75\% of Ugandan children experienced at least one type of violence in childhood. 1 in 3 girls and 1 in 4 boys experienced sexual violence. $18 \%$ of girls and $31 \%$ of boys who experienced sexual violence first experienced it in school. Violence and abuse are an omnipresent threat for street children. Walakira, Ddumba-Nyanzi, Lishan, and Baizerman (2014) investigated the experiences of 668 street children (aged 11 - 17 years) across seven geographic regions in Uganda. $76 \%$ of all children had subjected to physical violence, $61 \%$ had experienced sexual abuse, while $89 \%$ of participants experienced emotional violence. Children themselves became perpetrators of violence to other children. Younger children were in high-risk categories of experiencing sexual abuse. The internalisation and reproduction of witnessed violence facilitate negative connotations of street children within the community and affects support structures that may be available (Walakira et al., 2014).

The American Psychiatric Association (APA) describes trauma as an experience that threatens death, injury, or the loss of physical integrity and leads to feelings of helplessness, terror, and fear (APA, 2000). If trauma occurs in childhood, the negative impact can persist into adult years (Edwards Holden, Felitti, \& Anda, 2003). Early childhood trauma includes neglect, abuse, and emotionally abusive incidents, which can impact early attachments. When children experience an unsafe relationship or one deemed to reject the child's trust in others, their perception of self or the world can be altered (Dye, 2018). Survivors of trauma can suffer from anxiety, 
Journal of Symbols \& Sandplay Therapy, Vol.12 No.1.

depression, anger, abandonment issues, difficulty with trust, unstable relationships, or rejection (Briere \& Jordan, 2009).

Some street children who grew up under these unique circumstances can suffer a dual burden as they experience inhibited physical and psychological growth. According to Van Blerk (2016), street children had to employ alternative and resourceful survival strategies to create and shape their lives in the city. The street children lack adequate primary care, feel rejected, abandoned, unprotected, and abused in their neighbourhoods. Previous research identified these children as a vulnerable group worthy of attention and intervention (Connolly, 2004). The exploitation experienced by the street children in a Johannesburg shelter led to chronic feelings of anxiety, suicidal ideation, and survival despair (Myburgh., Moolla, \& Poggenpoel, 2015). Their exposure to these adverse life events in early childhood and adolescence causes traumatic impact, which often increases the risks for problematic issues with addiction, physical, emotional, social, behavioural, academic, and psychological health (Roncević et al., 2013). A persistent threat to the child is a potent source of adaptive survival responses when an ongoing threat is active e.g. anxiety, depression, behavioural impulsivity, and stress, these later become maladaptive when the incessant threat is removed or weakened (Meacham \& Bergstrom, 2016).

According to the World Health Organisation (WHO), various mental health diagnoses are contingent to a great extent upon the social, economic, and physical environment in which we live (WHO, 2014). Street children are subjected to many social inequalities previously described and are therefore at higher risk of many common psychological disorders because of greater exposure and vulnerability. Consequently, it emerges that an inquiry with greater insight and understanding of the street children's peculiar needs are paramount and further involvement of these children in the decision-making process that influences their development and future, is necessary to develop successful members of the society (Myburgh et al., 2015). According to Maslow (1943), an individual meets essential needs before achieving further developmental needs. The model is based on the individual meeting the basic needs of having a home that feels secure and safe. If the basic needs are not met, then individuals will struggle to overcome challenges such as addiction, psychiatric symptoms or education (Henwood, Derejko, Couture, \& Padgett, 2015; Greenwood, Stefancic \& Tsemberis, 2013). Maslow further posits that need gratification is not only a means of relieving frustrations but provides the basis for growth and the realisation of self-actualisation. In line with this, Meyer (1997) conveys the barrier for street 
children to develop their full potential and abilities while on the streets, which may contradict their developmental prospects. Likewise, Nasir, Khalid, and Shoukat (2014) correlated Maslow's theory to the emergence of street children and their psychological deficiencies and needs.

Early therapeutic intervention, empathy, and unconditional positive regard are essential and, therefore, warranted to avert the chronic and disruptive consequence of these adversities (Glaser, 2000). Ramos and de Matta (2008) highlight that if individuals do not improve after an intervention using a therapeutic technique for their traumatic symptoms trauma may become sedimented in subcortical structures' meaning it will not be verbalised and will remain in the unconscious. Non-verbal techniques may be an effective treatment approach that reduces or has no risk of the individual being re-traumatised. As rightly connoted that "the search for the self is associated with creativity in playing and only in playing that the individual child can be creative and enables an individual to use the whole personality, and it is only in being creative that the individual discovers the self' (Winnicott, 1971, pp. 54).

\section{Sandplay Therapy (SPT)}

The idea of using a sandtray began with Lowenfeld (1939), with the sandtray used as a way of enabling children to express themselves and their inner world. SPT makes unconscious material accessible (Kalff, 1989) and allows the client to create a picture of his/her inner world (Mitchell \& Friedman, 1994). During the sandplay process, consciousness relaxes, enabling the unconscious material to surface in the sand or with chosen miniatures. This process enables the unconscious to gain a voice during disturbance while also bringing clarity to courage and strengths, which may have gone previously unrecognised (Punnett \& Canfield, 2020).

Theorists have suggested that the client's creations while using the sandtray, are a physical extension of their internal processes (Isom, Groves-Radomski, \& McConaha, 2015). SPT is versatile due to being appropriate for most ages, cultures, problems, and theoretical frameworks (Ramsey, 2014; Sangganjanavanich \& Magnuson, 2011). In addition, the use of sandplay therapy is another way for individuals to express themselves, with the benefit of utilising the sandtray being that the client can express ideas for which they cannot verbalise or describe (McCormick, Rosenblad, \& Newmeyer, 2020). This can present the sandtray as merely a medium for communicating, while the figures can be considered as the client's words (Homeyer \& Sweeney, 
Journal of Symbols \& Sandplay Therapy, Vol.12 No.1.

2017). This non-verbal communication method provides a means for those from different cultures and languages to understand and relate to each other; "...it provides a window to see into the culture and experience of another person" (Ramsey, 2014, pp. 545).

Sand play therapy consists of using a tray that is approximately 18 by 24 inches and is $3-4$ inches in depth. The tray should be painted blue on the inside so that the bottom of the tray can represent water and the sides can represent 'a skyline'. A collection of miniatures can represent various categories such as vehicles, people, wild and domestic animals, buildings or religious/mystical/spiritual figures. Using these figures enables the individual to create scenes within the sandtray (Lyles \& Homeyer, 2015). Campbell (2004) states that SPT is developmentally appropriate and play-based, and it can be useful to use alongside other behavioural techniques. Using SPT is also believed to meet the needs of children with socioemotional and cognitive difficulties better than traditional therapies, in which talking is the method of expression.

\section{The Use of the Sand play therapy as an Intervention}

From the perspective of the therapist, one may gain a deeper understanding of children's inner worlds. From the children's perspective, they may gain a deeper understanding of each other's inner worlds. Considering the degree of trauma experienced by the street children, intrinsically linked with delays to language acquisition and emotion regulation, SPT appears to be a viable choice of intervention for them (Carey, 1990). SPT has become a popular method within several countries due to its nonverbal approach; it can be used by those from different ethnic backgrounds and can also with individuals who experience difficulties with language and expression of thoughts (Kalff, 1991). SPT can consist of two stages: first, the construction of a picture and, second, the client sharing what this picture consists of, specifically their story or ideas regarding the picture they constructed. The therapist may then ask further questions regarding the clients' ideas and the figures used within the picture (Roesler, 2019).

According to Jang (2009), Sandplay therapy can be used as an intervention with individuals experiencing difficulties in self-expression, loneliness, or anxiety. SPT has been described by Nasab and Alipour (2015) as a type of play therapy with the therapist being a facilitator in the process and allowing the child to express the emotions that they are experiencing freely. The use 
of the sandtray and the miniatures enables the child to create a concrete expression of their mental image. According to Weinrib (1983), the creation of a sand picture is referred to as both a creative and symbolic act that involves the imagination freeing 'neurotically fixated energy' and focusing this energy into a creative format which can in itself be a healing experience for the individual (Weinrib, 1983, pp. 23). In addition, the use of groups within the play therapy environment has shown improvements in participants' acceptance of others, self-acceptance, self-respect, social skills, and decreases in anxiety and depression (Baggerly \& Parker, 2005). Research has shown that play therapy techniques can positively improve social skills, behavioural change, self-concepts, and anxiety (Bratton \& Ray, 2002).

Implementing SPT group therapy format may be beneficial. Group therapy facilitates a supportive space where children and adolescents can observe emotional disclosure from peers and 'explore the questions of group identity...' (Gallo-Lopez et al., 2010. p.23). Through a group format, sand-play may support a 'common vision' where participants feel included and connected (Gallo-Lopez et al., 2010). Using group work with the sandtray can provide many opportunities to build relationships and improve communication skills. In addition, sand trays can aid a child in making a disclosure, develop an individual's self-awareness, develop the ability to enter the world of others and provide an opportunity for others to enter their world, in addition to developing a sense of community (Homeyer et al., 2017).

Furthermore, Kalff (1991) found that SPT group sessions with children led to decreased aggressive and delinquent behaviours while improving their relationships with peers. The use of SPT within groups also encourages communication among the group members, which may lead to changes in internal relations, in turn leading to improvements in an individual's confidence, self-expression or the increase in trust as well as a sense of belongingness among the members (Corey \& Corey, 2006). Jang (2012) utilised a sandplay intervention with the therapists and the group members listening to others' stories, leading to social interactions and anxiety reduction. This study showed an overall reduction in participants' loneliness and anxiety during social interactions with the social interactions, sympathy and support offered during the use of SPT named as what led to these changes for participants.

The authors considered SPT to be an excellent medium to observe the children's unconscious manifest in the conscious sphere. The children, who had experienced trauma in early childhood and are not proficient in the English language with minimal educational attainment levels due 
Journal of Symbols \& Sandplay Therapy, Vol.12 No.1.

to their socioeconomic status, are exemplary of the appropriate use of SPT because of its minimal requirement of traditional talk therapy.

\section{Objectives}

This study evaluates how group SPT may impact participant's psychological health and resilience, and explores the themes that participants expressed during SPT. The goal is to assess the psychological and behavioural symptomatology before and after Sand play therapy participation to establish the efficacy for facilitating positive psychological and sociological development.

The following questions will be addressed:

1. What are the predominant themes in the children's sandplay creations? What processes or psychological presentations can be deduced from examining these themes?

2. Is sandplay therapy effective in improving the children's prosocial behaviour, resilience, and positive peer relationships as measured by the Strengths and Difficulties Questionnaire (SDQ)?

3. What are the effects of Sandplay therapy on perceived anxiety and depression of the Children? Is there an overall decrease in Revised Child Anxiety and Depression Scale (RCADS) T-Scores after engaging in Sandplay sessions?

\section{I . Research Methodology}

\section{Participants}

Fifteen Ugandan mixed-gender children (9 females and 6 males) at a Child Protection and Welfare Centre (CPWC) in Kabale were selected through convenient purposive sampling. The study conveniently identified a group of children who were originally assigned to a project worker under the supervision of one of the study researchers. No control group was used in this study; the participants included in the study were a pre-existing cohort and given the levels of hardship and trauma that had been experienced by all the children in the CPWC, there were ethical concerns regarding excluding a subset from participating in a potentially beneficial 
intervention, given the absence of any other psychotherapeutic care. The average age of participants was 15.27 years, with the median age being 17 years. Children were split into groups according to their attendance at the centre as follows; 5 day school children (age range: 17 - 19 years), 5 boarding children (age range: 7 - 20 years), 5 street children (age range: 4 17 years). All fifteen children assented to participate in the study.

The three groups of children explored in this article experienced life by living and sleeping on the streets in the country of Uganda. These children lived and wandered on the streets while engaging in menial duties to survive in the harsh conditions of street life. The groups of children are deemed vulnerable, having been subjected to crime and mental health challenges during their lives. Accessibility to the children was made possible by the efforts of a Child Protection and Welfare Centre that rescues and shelters children from the peril of the streets. The group of children catered for at the centre are classified as: Boarding school children (BSC) were rescued from the streets, and this group consisted of five children. They live in a boarding school during term time and visit the CPWC at the weekends or during holiday periods. Day school children (DSC) are resident at the CPWC and attend the local school as day students. The children have access to primary care, education and social engagements within the CPWC. The street children (SC) are a group of children with no fixed abode, currently living on the streets due to lack of resources in their family homes, neighbourhoods, or CPWC. Some of these children find it challenging to adapt to the regimented sheltered culture and would willingly return to the streets where they are so accustomed.

\section{Data collection}

A quasi experimental mixed-methods design was used for this study. Data presented in this article originated from multiple sources, qualitative and quantitative. Qualitative data were gathered from the children's SPT creation that was presented by the project workers and analysed by the researchers. The visual data was collected over nine weeks, with the children engaging in a forty minutes group session once every week. The quantitative data was compiled by administering the Strengths and Difficulties Questionnaire (SDQ) and RCADS questionnaires at two-time points. 
Journal of Symbols \& Sandplay Therapy, Vol.12 No.1.

\section{Procedure}

The groups consisted of fifteen participants from the CPWC, each group had been allocated five children according to their attendance status at the CPWC. The participants, namely the children $\mathrm{x} 15$, project worker $\mathrm{x} 1$ and research assistant $\mathrm{x} 1$, were debriefed on the research details in an information-based exercise. The project worker had received basic training in SPT 2 years prior to the study by a child and adult Jungian and had continued with the practice since their training. The staff actively conduct SPT at the centre, with the children being aware of the sandplay process from engaging previously in individual sessions. All the children had previous individual SPT, it is unknown how many sessions had been conducted before this study as the engagement varied between the children. For the purpose of historical awareness on pre-existing symptoms, seven sessions individual sandplay creations of some of the children were made available for observations.

All children selected were allocated to the experimental group as there were no controls in this study. The study is a within-subjects design that looked at the effect of SPT at two time points. Questionnaires were administered to the three groups before intervention as baseline (T1) and after the Ninth session (T2). Each group of children was identified to create sandplay scenes with all the sandplay creations photographed for reference. The sandplay sessions lasted approximately forty-five minutes and were non-directed, except for the fourth session. The project worker followed up on collating the children's explanation of their contributions and creations without interference or intervention in their creativity. The project worker supported a safe, reassured, interactive and protected environment for the children.

The research team consisted of seven assistant psychologists (AP), including one AP who acted as a coordinator and supervisor to the project worker based in Uganda. The coordinator role consisted of supervising, liaising, advising, and organising the process regarding the data collection. The research team conducted online meetings where issues concerning the research were discussed. During these online meetings, relevant literature and theories were discussed. The research design, objectives, hypotheses, observed themes, coding style, expected outcomes, critiques, delegations, other contributions and relevant aspects of the research were discussed. 


\section{Sand Play Formations}

Considering the degree of trauma experienced by the street children, intrinsically linked with delays to language acquisition and emotion regulation, SPT appears to be a viable intervention choice. Implementing a group therapy format is considered particularly beneficial for their presentations. The group SPT facilitates a supportive space, where the children and adolescents can observe emotional disclosure from peers and 'explore the questions of group identity...' (Gallo-Lopez et al., 2010, p. 23).

The SPT delivered in this research is of the Kalffian approach developed by Dora M. Kalff of Switzerland in the 1950s. A sand tray, sand, and various figurines reflecting both real-life and fantasy symbols were used for the current study. The tray was $20 \times 30 \times 3$ inches in size, and the dimensions of the tray are such that clients could easily access all sides and exert physical and visual control over the tray (Kestly, 2010).

A photograph of the sandplay creation of the children was submitted (Figure 1). Where applicable, the creator's responses were reported, and notable information on observations by the project workers was also submitted for contents and emerging themes to be analysed by the Europe based researchers. The themes were categorised by how pronounced and commonly

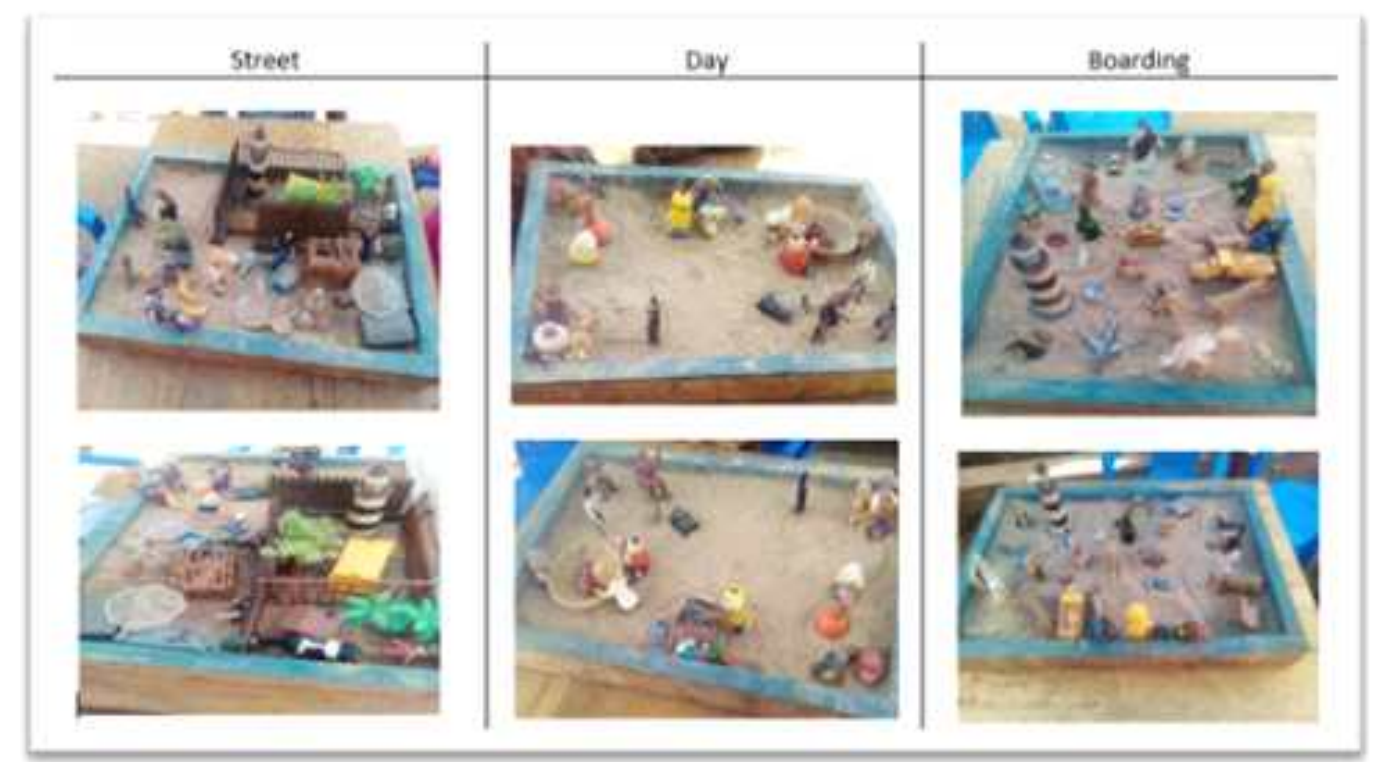

Figure 1. Week One Sand Play Formation 
Journal of Symbols \& Sandplay Therapy, Vol.12 No.1.

representative they were represented from the collated sandplay creations.

\section{Thematic Analysis}

In terms of qualitative analysis, the sandplay of the three groups of children were analysed thematically by two researchers. The six steps outlined by Braun and Clarke (2006) were followed: familiarisation, initial coding, searching for themes, reviewing themes, defining themes, and producing a report.

At the familiarisation stage, to become thoroughly familiar with the data, the individual worlds, and histories of some of the children, seven weeks of the children's individual and nine weeks of group sandplay for all children were reviewed by the researchers. At this stage, a Sandplay Categorical Checklist for Sandplay Analysis developed by Geri Grubbs (2005) was used to explore the group sandplay creations from a Jungian/Kalffian perspective, examining dynamics such as movement, boundaries, sparsity/crowdedness of the tray and relationship between the figures in the tray. In addition to several key Jungian themes such as worship, aggression, and work/play.

The three phases of sandplay analysis illustrated by Grubbs (2005) include

- The thematic content of the tray and the process involved in its creation.

- The creator's personal account of the tray's significance

- The progressive and regressive changes between the sandplay worlds.

The initial evaluation and coding of themes were performed separately, the themes were then reviewed cooperatively by the researchers. At the review stage, particular instances of ambiguous themes were referred to the trays with their descriptions and initial codes; the final consensus was achieved, and the themes redefined.

\section{Quantitative Data}

Quantitative data was obtained from disseminating SDQ and RCADS at time 1 and time 2. Self-reports were completed by all children for the RCADS $(n=15)$ and proxy reports were also completed by the project workers for all children for the SDQ ( $n=15)$ and RCADS ( $n=15)$. 
Where a participant was unable to read or write, a project worker was assigned to communicate the contents of the questionnaire to the child. Where the participant could not comprehend the SDQ and RCADS, children and project workers then asked follow-up questions for clarification. Some children were orphans or had lost contact with their parents. In this study, the resident project worker at the CPWC completed the parent version of the questionnaires as they were the child's guardian. This study engaged all the children in completing the self-report questionnaire with the support of the assistant who asked the questions and recorded their responses.

\section{1) Strengths and Difficulties Questionnaire (SDQ)}

The SDQ (Goodman, 2001) is a measure of prosocial behaviour and psychopathology for children and youths between the ages of 2 to 18 years. The questionnaire can be completed by a parent, guardian, carer, or teacher for 2-17-year-olds. Self-reports can be completed by 11 to 17-year-olds. The SDQ takes five to ten minutes to complete and consists of 20 items divided into five subscales containing five items each. The subscales are as follows: emotional problems, conduct problems, hyperactivity-inattention, peer problems and prosocial problems (Goodman, 2001). Respondents indicate on a 3-point Likert scale how much an attribute applies to the target child $(0=$ Not True, $1=$ Somewhat True, $2=$ Certainly True $)$. A cumulative total difficulty score is generated from the five subscales. The SDQ has shown moderate test-retest reliability (Yao et al., 2009). The SDQ has previously shown good concurrent validity and good discriminant validity (Muris, Meester \& Van den Berg, 2003; Lundh, Wangby-Lundh \& Bjarehed, 2008). Studies have been inconclusive on its internal consistency measure, with articles showing robust response (Yao et al., 2009); satisfactory outcome (Goodman, 2001); with some articles showing low internal consistency and subsequently recommending using the SDQ for screening only (Mieloo et al., 2012).

\section{2) Revised Child Anxiety and Depression Scale (RCADS)}

The RCADS (Chorpita, Yim, Moffitt, Umemoto, \& Francis, 2000) is a 47-item self-report questionnaire that assesses anxiety and depression symptoms on a four-point Likert scale $(0=$ never, 3 = always). There are five anxiety scales including obsessive-compulsive disorder (6 items; "I can't seem to get bad or silly thoughts out of my head"), separation anxiety (7 items; "I 
Journal of Symbols \& Sandplay Therapy, Vol.12 No.1.

worry when I go to bed at night"), social phobia (9 items; "I feel scared when I take a test"), generalized anxiety disorder ( 7 items; "I worry about things") and panic disorder (9 items; "When I have a problem I feel shaky:). The depression scale consists of 10 items ("I cannot think clearly"). A total anxiety Score is generated from the summation of the five anxiety subscales, and the Total Internalising Scale the sum of all six subscales. The RCADS has demonstrated excellent reliability and validity (Becker et al., 2019).

\section{Data Analysis}

The aggregated quantitative data was collated and scored using an excel tool. IBM SPSS Statistics version 27 was used to analyse the data collated from the SDQ and RCADS were submitted to respective one-way analyses of variance to ascertain the difference between groups, then a follow-up Tukey post hoc test was conducted to highlight the specific differences between groups. T-tests analysed the difference between overall pre-and post-intervention scores. A significance level of .05 was selected for all statistical tests. The dependent variables of interest were the pre-and post-intervention SDQ and RCADS scores.

\section{Ethical Considerations}

The researchers observed some very important ethical practices during this research. Ethical measures such as autonomy, beneficence, non-maleficence, and justice were adhered to for the duration of the research. The researchers sought consent by providing participants and their project worker with study documentations and consent forms in advance of the study. Participants below 18years assented and the guardian provided informed consent for their participation in the study. The guardian in this study is the resident project worker who had the children in her care. All participants were informed of the right to decline or withdraw from the study at any time prior to the date being anonymised. Project workers are trained personnel in social work and are aware of the safeguarding procedures in place. The management and research team were to be consulted where safeguarding disclosures occurred that jeopardize the safety and welfare of any child participant. The project worker was also trained and informed to be sensitive, observant, and empathetic to the emotional needs of the 
children during their participation in the study. Any such child that requires further counselling were referred to professional mental health services. All data collated were encrypted and password protected in a secure laptop held in a locked area. This data was confidential in compliance with data protection regulations and all datasets were also observed for anonymity whereby a unique identification number was allocated to each participant. Furthermore, data exchange was used among researchers however this exchange of electronic data was purposive and deleted after achieving the goal it was sent for. All protected transcribed and raw data will be destroyed two years after publication and the benefits of this study outweigh any burden associated with participation in the research. Ethical approval was not sought for this study as it was conducted in an observational setting of pre-existing groups and therapeutic interventions.

\section{ПI. Results}

\section{Qualitative Results}

The researchers abstracted out themes from the initial coding items (see Table 1) These were

Table 1. Coding information for qualitative data

\begin{tabular}{ccc}
\hline Coding qualitative data. ST W14 & Codes & Themes \\
\hline Extracts from the sandtray description & Recreation & Recreation-self-development-self-nurturance \\
\hline Children went to a national park on a plane & Community spirit & Community-love-celebration \\
\hline They travelled as a group & Leisure activities & Recreation-self-development-self-nurturance \\
Children walked around the national park and & Plentifulness & Recreation-self-development-self-nurturance \\
\hline $\begin{array}{c}\text { Children owned resources to organise the trip } \\
\text { Two of the children worked as a pilot and }\end{array}$ & Future, good jobs & Recreation-self-development-self-nurturance \\
Children organised transport for the group, & Being empowered & Giving help-leadership-empowerment \\
one of them was piloting a helicopter & Safety concerns & \\
A fence was installed to protect children \\
from wild animals
\end{tabular}


Journal of Symbols \& Sandplay Therapy, Vol.12 No.1.

later re-evaluated to give a final theme.

Over the course of these steps, the theme groupings noted were security-danger, basic needs, community-love-celebration, giving help-leadership-empowerment, recreation-self-development-selfnurturance, education, and seeking help-faith.

It was found that across all groups, the theme giving help-leadership-empowerment was expressed 37 times, basic needs 35 times, recreation-self-development-self-nurturance 35 times, community-love-celebration 26 times, security-danger 22 times, education 8 times, seeking help-faith 7 times. Appendix A shows the relative proportions of how frequently each theme grouping was expressed across groups and weeks.

As shown in Figure 2 below, recreation-self-development-self-nurturance for street children was expressed at $30.2 \%$, which is more than twice that of the other two groups (16.3\% for day schoolers and $13.8 \%$ for boarding school students).

The topic of basic needs, such as food and sleep were expressed most often by the group of boarding school children (29.3\%), compared to $20.4 \%$ in day school children and $12.7 \%$ by street children. The concept of giving help-leadership-empowerment was almost equally represented in the work across all groups. Street children used this theme 22.2\%, day school children $-24.5 \%$, and boarding school children $-19.9 \%$.

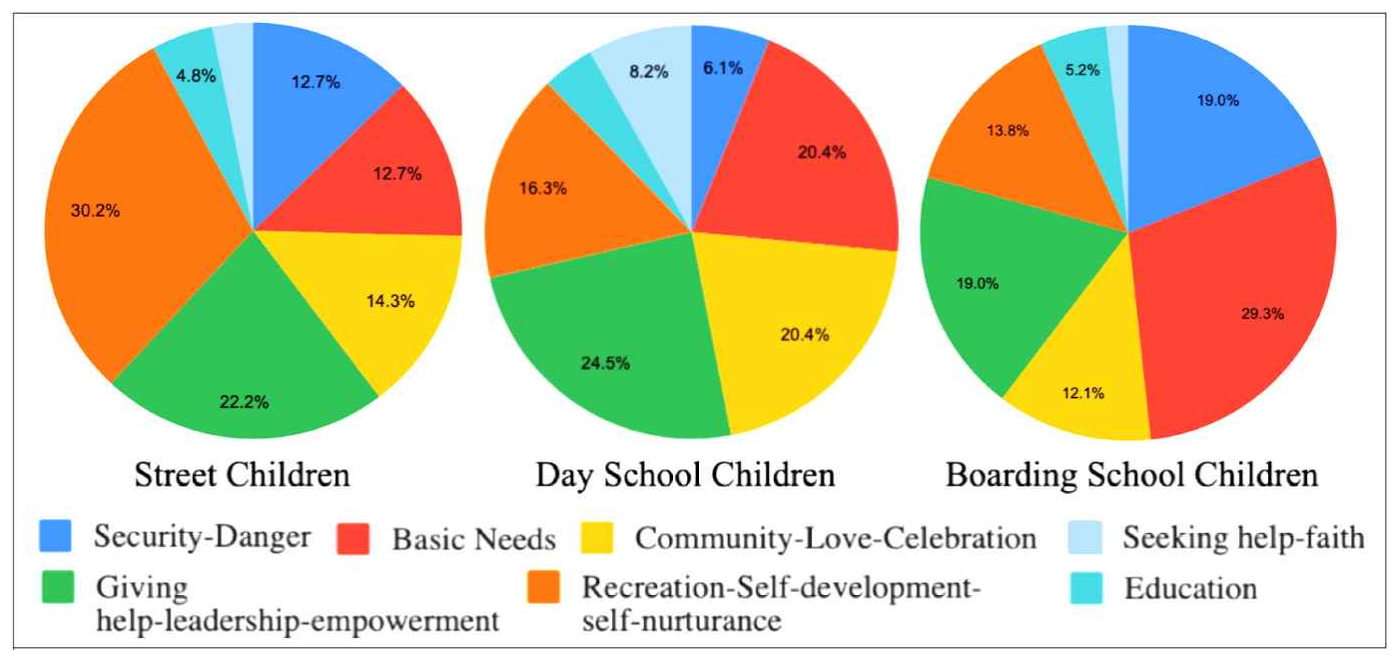

Figure 2. Proportion of each theme by Group 
Interestingly, the theme of security-danger was primarily expressed in the boarding school children $(19 \%)$ in comparison to the street children $(12.7 \%)$ and the day school children $(6.1 \%)$. Similarly, the expressions for community-love-celebration were expressed predominantly among the day school children (20.4\%) and the street children (14.3\%) than it emerged in the boarding school children (12.1\%) sand trays. However, it was the case that education and seeking help-faith were among the lowest themes represented in the children's sandplay formations.

\section{Integration}

A rating to what extent the group sand trays were integrated was also included. This rating is composed of a scale from 1 to 5. 1 represented a group tray with no interaction between the children's sandplay. 2 involved 1-2 interactions or thematic similarities in the absence of an overall theme. 3 represented numerous interactions or similarities in the absence of an overall theme. 4 indicated significant interaction or similarity between most but not all the group regardless of an overall theme. Finally, 5 was a fully integrated scene involving all children in the group. This was performed individually, with each reviewer assessing the other's score to increase inter-rater reliability. Integration was low across groups in the first two weeks, increasing after that (See table 2).

Table 2. Measure of integration - Frequency of themes over the 9-week period

\begin{tabular}{|c|c|c|c|c|c|c|c|c|c|c|c|c|c|c|c|c|c|c|c|c|c|c|c|c|c|c|c|c|c|c|}
\hline \multirow{2}{*}{$\begin{array}{l}\text { Week } \\
\text { Group }\end{array}$} & \multirow[b]{2}{*}{ ST } & \multicolumn{2}{|c|}{ Week 1} & \multicolumn{3}{|c|}{ Week 2} & \multicolumn{3}{|c|}{ Week 3} & \multicolumn{3}{|c|}{ Week 4} & \multicolumn{3}{|c|}{ Week 5} & \multicolumn{3}{|c|}{ Week 6} & \multicolumn{3}{|c|}{ Week 7} & \multicolumn{3}{|c|}{ Week 8} & \multicolumn{3}{|c|}{ Week 9} & \multicolumn{3}{|c|}{ Total } \\
\hline & & DS & BS & ST & DS & BS & ST & DS & BS & ST & DS & BS & ST & DS & BS & ST & DS & BS & ST & DS & BS & ST & DS & BS & ST & DS & BS & ST & DS & BS \\
\hline Theme & & & & & & & & & & & & & & & & & & & & & & & & & & & & & & \\
\hline $\begin{array}{l}\text { Security- } \\
\text { danger }\end{array}$ & 1 & 1 & 1 & 1 & & 3 & & 1 & 1 & 1 & & & 1 & & 1 & & & & 1 & & 1 & 1 & & & 2 & & 1 & 8 & 3 & 11 \\
\hline Basic Needs & & 1 & 2 & 1 & & 1 & & & & & & & & 1 & & & & 2 & & & 4 & & & & & & 4 & 8 & 10 & 17 \\
\hline $\begin{array}{l}\text { Community- } \\
\text { Love- } \\
\text { Celebration }\end{array}$ & & 1 & 2 & 1 & 1 & & 4 & 2 & 2 & & 3 & 3 & & & 1 & 2 & & 1 & 1 & & & 1 & & & & & & 9 & 10 & 7 \\
\hline $\begin{array}{l}\text { Giving help- } \\
\text { leadership- } \\
\text { empowerment }\end{array}$ & & 2 & 1 & 2 & 1 & 2 & 3 & 2 & 2 & 1 & 3 & 3 & 1 & 1 & 1 & 4 & & 1 & & & 4 & 1 & & & 2 & & 1 & 14 & 12 & 11 \\
\hline $\begin{array}{l}\text { Recreation- } \\
\text { Self- } \\
\text { development- } \\
\text { self-nurturance }\end{array}$ & & & & & 1 & 1 & 1 & & & 3 & 2 & 2 & 2 & 1 & 1 & & & 1 & & & & 4 & & 5 & 3 & & & 19 & 8 & 8 \\
\hline Education & & & 1 & 1 & & & & & & & & & & 1 & 1 & & & & 2 & & & & & & & & & 3 & 2 & 3 \\
\hline $\begin{array}{l}\text { Seeking help- } \\
\text { faith }\end{array}$ & 2 & 1 & 1 & & 2 & & & & & & & & & 1 & & & & & & & & & & & & & & 2 & 4 & 1 \\
\hline $\begin{array}{l}\text { Group vs } \\
\text { Individual } \\
\text { (Integration) }\end{array}$ & 3 & 1 & 1 & 1 & 1 & 2 & 5 & 5 & 5 & 2 & 5 & 3 & 5 & 5 & 3 & 5 & 5 & 5 & 5 & 5 & 5 & 5 & 4 & 4 & 2 & 5 & 5 & 33 & 36 & 32 \\
\hline
\end{tabular}




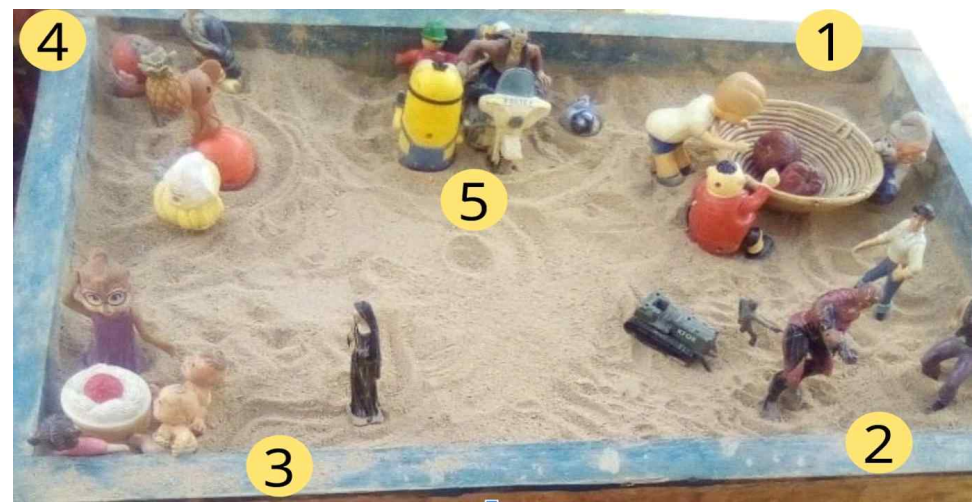

Figure 3a. Example of a sandplay creation rated 1 for integration

Children created individual stories in distinct sections of the tray. Descriptions starting from the top right, clockwise:

1. This child used a round basket representing a garbage centre and people surrounding it looking for food.

2. This child used figures of men to create a story about rebels, who were fighting, and one was killed by a bomb.

3. This child placed a cake in the tray and figures of children around the cake. They were celebrating her birthday party with her friends when an angel came to celebrate with them.

4. This child created a story about how she helped a person and that person brought her gifts in the form of pineapple and apples.

5. This child created a story where someone was riding a motorcycle and other people around him were asking for a lift.

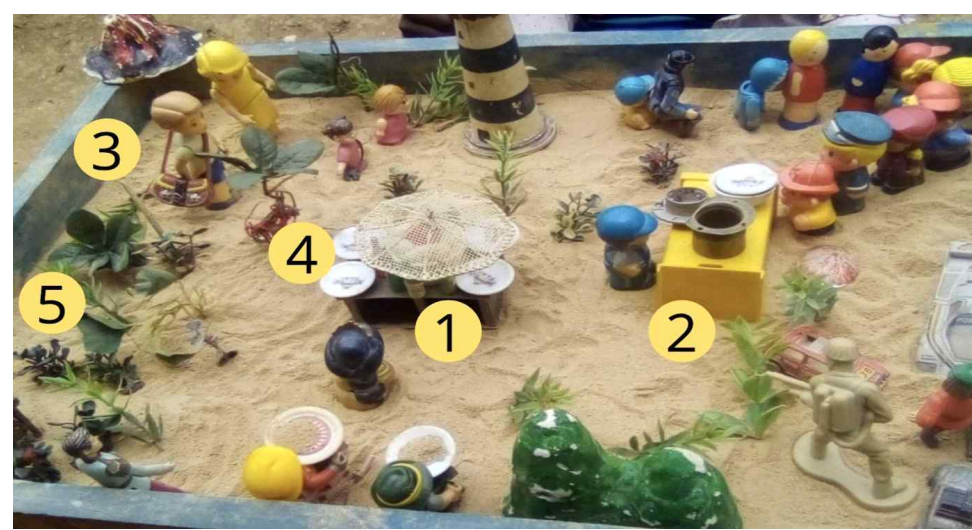

Figure $3 b$. Example of a sandplay creation rated 5 for integration 
The group of children created a planning committee to organise a party.

1. This child placed a cake at the centre of the sandtray. Children will cut and serve the cake to celebrate the birthday of one of the children.

2. This child organized a serving table that contained plates, dishes and food for group members and guests.

3. This child organized photography and invited guests. She was also in charge of serving food.

4. Two other children were in charge of decoration and organised seating in the tent. They used flowers and plants to decorate the space.

5. Children commented that everyone had a great time at the party. They sang, danced, and participated in a fashion show.

\section{Quantitative Results}

A significance level of .05 was selected for all statistical tests. The dependent variables of interest were the pre- and post-intervention SDQ and RCADS scores.

\section{1) Demographic Data}

Demographic characteristics for three groups; boarding school; day school children; street children are displayed below (Table 3).

Table 3. Demographic information of participants

\begin{tabular}{|c|c|c|c|c|c|}
\hline & & $\begin{array}{l}\text { Boarding School } \\
\text { Children }(n=5)\end{array}$ & $\begin{array}{l}\text { Day School Children } \\
(n=5)\end{array}$ & $\begin{array}{l}\text { Street Children } \\
(n=5)\end{array}$ & \\
\hline & & $\begin{array}{l}\mathrm{M} \pm S D \\
\%\end{array}$ & $\mathrm{M} \pm S D$ & $\mathrm{M} \pm S D$ & $p$ \\
\hline Age & & $14.6 \pm 4.5$ & $8.6 \pm 1.07$ & $11.0 \pm 4.4$ & .10 \\
\hline \multirow[t]{2}{*}{ Sex } & Male & $80 \%$ & $40 \%$ & $60 \%$ & \\
\hline & Female & $20 \%$ & $60 \%$ & $40 \%$ & \\
\hline
\end{tabular}

\section{2) Strength and Difficulties Questionnaire (SDQ)}

\section{(1) SDQ: Carer Report}

Findings from pre and post-test Carer reported SDQs for the entire group are presented in Table 3. Results indicate that the group SPT intervention had a statistically significant effect in reducing total difficulty scores at post-test $(t=-14.73, p<.001)$. Elevated Scores $(\geq 17)$ in Total 
Journal of Symbols \& Sandplay Therapy, Vol.12 No.1.

Difficulties are considered clinically significant (Goodman, 2001). At pre-test, 100\% of children scored within the clinical range for Total Difficulties. Post-test this reduced to $13.3 \%$ scoring within the clinical range.

(2) Between Group Findings

A one-way analysis of variance was conducted to analyse differences in pre-test and post-test carer reported SDQs following the nine-week sand play therapy intervention. Results indicate that there was no significant difference between pre and post-test total SDQ scores.

Analysis further revealed significant differences between groups conduct problems at pre-test $\mathrm{F}$ $(2,12)=6.12, \mathrm{p}=.006$, and post-test $\mathrm{F}(2,12)=5.04, \mathrm{p}=0.014$ respectively, showing day school $(\mathrm{M}=3.4, \mathrm{SD}=1.34)$ differed significantly from street children $(\mathrm{M}=6.6, \mathrm{SD}=$ $2.08)$ and boarding school $(\mathrm{M}=4.2, \mathrm{SD}=2.28)$ at pre-test and likewise at post-test day school children $(\mathrm{M}=1.4, \mathrm{SD}=0.84)$ differed from boarding school $(\mathrm{M}=3.6, \mathrm{SD}=2.3)$ and street children $(\mathrm{M}=2.8, \mathrm{SD}=1.03)$. Post hoc comparisons using Tukey hsd showed that day school children $(M=3.4, S D=1.34)$ differed significantly from street children $(M=6.6$, $\mathrm{SD}=2.8)$ in pre-test conduct problem scores. This trend did not continue at post-test.

The total difficulties questionnaire scores for the three groups appear in (Table 4), this is the total generated scores from all four subscales except the prosocial subscale, a significant reduction in scores was reported in (Table 4). A categorisation specification (Goodman, 2001) rated our pre-test score (25.93) as very high and abnormal classification whereas subsequent to intervention this has reduced to (13.47), rating in the normal and close to average range.

Table 4. Changes Carer Reported Total Difficulties Scores pre and post-test $(n=15)$

\begin{tabular}{lccc}
\hline Item & & Score M(SD) & \multicolumn{1}{c}{$\boldsymbol{t}$} \\
\hline $\begin{array}{l}\text { Total Difficulties } \\
\text { Score }\end{array}$ & Pre & $25.93(4.29)$ & $-14.73^{*}$ \\
& & & \\
& Post & $13.47(4.58)$ & \\
\hline$* p<.001$ & & &
\end{tabular}

Similarly, significant differences were observed in prosocial problems pre-test, $F(2,12)=8.02$, 
Table 5. Comparison of Carer reports of SDQ scores between the three groups

\begin{tabular}{|c|c|c|c|c|c|}
\hline \multirow[t]{2}{*}{ Item } & & \multirow[t]{2}{*}{$\begin{array}{l}\text { Boarding } \\
\text { School } \\
\text { Children } \\
(\mathrm{n}=5) \\
\text { M (SD) } \\
\end{array}$} & \multirow[t]{2}{*}{$\begin{array}{l}\text { Day } \\
\text { School } \\
\text { Children } \\
(n=5) \\
\text { M(SD) }\end{array}$} & \multicolumn{2}{|l|}{$\begin{array}{l}\text { Street } \\
\text { Children } \\
(n=5)\end{array}$} \\
\hline & & & & M(SD) & $P$ \\
\hline \multirow{2}{*}{$\begin{array}{l}\text { Emotional } \\
\text { Problems }\end{array}$} & Pre & $8.0(2.0)$ & $9.4(.55)$ & $9.4(.55)$ & .16 \\
\hline & Post & $4.2(.837)$ & $5.0(1.22)$ & $5.4(1.14)$ & .24 \\
\hline \multirow{2}{*}{$\begin{array}{l}\text { Conduct } \\
\text { Problems }\end{array}$} & Pre & $4.2(2.28)$ & $3.4(1.34)$ & $6.6(2.8)$ & $.006 * *$ \\
\hline & Post & $3.6(2.3)$ & $1.4(.84)$ & $2.8(1.03)$ & $.014 * *$ \\
\hline \multirow{2}{*}{$\begin{array}{l}\text { Hyperactivity } \\
\text { Problems }\end{array}$} & Pre & $7.2(2.58)$ & $6.8(.83)$ & $7.2(1.30)$ & .82 \\
\hline & Post & $4.4(3.4)$ & $2.6(1.0)$ & $2.8(1.03)$ & .14 \\
\hline \multirow{2}{*}{$\begin{array}{l}\text { Peer } \\
\text { Problems }\end{array}$} & Pre & $4.2(1.48)$ & $4.8(1.78)$ & $3.8(1.78)$ & .65 \\
\hline & Post & $2.2(2.0)$ & $3.0(2.2)$ & $3.6(1.14)$ & .51 \\
\hline \multirow{2}{*}{$\begin{array}{l}\text { Prosocial } \\
\text { Problems }\end{array}$} & Pre & $5.2(1.92)$ & $8.6(1.67)$ & $4.4(1.67)$ & $.00 * *$ \\
\hline & Post & $8.4(1.5)$ & $9.2(0.44)$ & $8.8(1.09)$ & .54 \\
\hline \multirow[t]{2}{*}{$\begin{array}{l}\text { Total SDQ } \\
\text { scores }\end{array}$} & Pre & $24.8(6.3)$ & $\begin{array}{l}26.0 \\
(3.16)\end{array}$ & $\begin{array}{l}27.0 \\
(3.74)\end{array}$ & .76 \\
\hline & Post & $14.0(7.7)$ & $\begin{array}{l}11.6 \\
(2.07)\end{array}$ & $14.0(2.1)$ & .58 \\
\hline
\end{tabular}

$p=$.006. Post hoc comparisons using the Tukey HSD test indicated that day school children $(\mathrm{M}=8.6, \mathrm{SD}=1.07)$ differed significantly from street children $(\mathrm{M}=4.4, \mathrm{SD}=1.67)$ and boarding school children $(\mathrm{M}=5.2, \mathrm{SD}=1.92)$ in prosocial problem scores (Table 5). This suggests day school children presented higher levels of Prosocial problems at baseline when compared to street and boarding children.

\section{3) Revised Children's Anxiety and Depression Scale (RCADS)}

(1) RCADS: Self-report

At pre-test, $66.6 \%$ of children scored within the clinical range ( $\mathrm{T}$ score $\geq 70$ ) for total anxiety and depression. Post-test, no children scored in the clinical range with $80 \%$ scoring in the normal range for anxiety and depression ( $\mathrm{T}$ score $\leq 65$ ). A significant reduction in total anxiety and depression self-reported scores was observed at post-test for the total group $(t=$ 
Journal of Symbols \& Sandplay Therapy, Vol.12 No.1.

Table 6. RCADS: Self reports total pre and post anxiety and depression scores $(n=15)$

\begin{tabular}{lccc}
\hline Item & & Score M(SD) & $t$ \\
\hline $\begin{array}{l}\text { Total Anxiety } \\
\begin{array}{l}\text { Depression } \\
\text { Scores }\end{array}\end{array}$ & Pre & $74.73(12.16)$ & $10.23^{*}$ \\
& & & \\
& Post & $55.67(8.81)$ & \\
\hline${ }^{*} p<.001$ & & &
\end{tabular}

$10.23, p<.001)$ as shown in (Table 6).

(2) Between Group Findings

There was a significant difference between the groups, at pre-intervention for obsessive compulsive disorder scores, $F(2,12)=4.686, p=0.03$. A significant difference between groups for generalised anxiety depression scores was also observed, $F(2,12)=5.298$, p $=.02$. RCADS data between the three groups appear in (Table 7).

(3) RCADS: Carer Reports

At pre-test, $93.3 \%$ of children scored within the clinical range for anxiety and depression. However, post-test result revealed one child scored in the clinical range. All other scores were in the normal range ( $\mathrm{T}$ score $\geq 65$ ). Results revealed that the group SPT had a statistically significant effect in reducing carer-reported total anxiety scores post-intervention $(t=9.55, p$ $<.001$ ). A significant decrease in total anxiety and depression scores was observed post-intervention $(t=11.40, p<.001)$.

The graphs in figure $4 \mathrm{a}$ and $4 \mathrm{~b}$ support the t-test showing the overall reduction observed at Time 2 after the nine sandplay sessions. The pre-test t-scores showed a high score of anxiety and depression levels in most of the children and the post-test t-scores highlights a reduction in the scores.

According to Chorpita et al (2000), t-scores below 65 are within the normal range, at borderline only $6 \%$ of youths in the general population have t-scores of 65-69 whereas at the clinical threshold, it was predicted $2 \%$ of the youth in general population present with t-scores 
Table 7. Comparison of RCADS self-reports between three groups

\begin{tabular}{|c|c|c|c|c|c|c|c|}
\hline \multirow[t]{2}{*}{ Item } & & \multirow[t]{2}{*}{$\begin{array}{l}\text { Boarding } \\
\text { School } \\
\text { Children } \\
(\mathrm{n}=5) \\
\text { M (SD) } \\
\end{array}$} & \multirow[t]{2}{*}{$\begin{array}{l}\text { Day School } \\
\text { Children } \\
(\mathrm{n}=5)\end{array}$} & \multirow[t]{2}{*}{$\begin{array}{l}\text { Street } \\
\text { Childre } \\
\text { n (n = } \\
\text { 5) } \\
\text { M(SD) } \\
\end{array}$} & \multicolumn{3}{|c|}{$95 \%$ CI } \\
\hline & & & & & $P$ & Lower & Upper \\
\hline $\begin{array}{l}\text { Total } \\
\text { Internalising }\end{array}$ & Pre & $\begin{array}{l}73.0 \\
(9.4)\end{array}$ & $\begin{array}{c}71.8 \\
(11.6)\end{array}$ & $\begin{array}{l}79.4 \\
(15.8)\end{array}$ & .604 & 68.0 & 81.4 \\
\hline & Post & $\begin{array}{l}54.4 \\
(8.6)\end{array}$ & $\begin{array}{l}51.80 \\
(7.66)\end{array}$ & $\begin{array}{l}60.8 \\
(9.2)\end{array}$ & .267 & 50.7 & 60.5 \\
\hline $\begin{array}{l}\text { Total } \\
\text { Anxiety }\end{array}$ & Pre & $\begin{array}{l}71.2 \\
(9.5)\end{array}$ & $\begin{array}{l}68.4 \\
(12.0)\end{array}$ & $\begin{array}{l}73.0 \\
(13.5)\end{array}$ & .828 & 64.7 & 77.0 \\
\hline & Post & $\begin{array}{l}52.0 \\
(5.7)\end{array}$ & $\begin{array}{l}52.6 \\
(7.7)\end{array}$ & $\begin{array}{l}56.8 \\
(7.3)\end{array}$ & .520 & 49.9 & 57.6 \\
\hline $\begin{array}{l}\text { Generalised } \\
\text { Anxiety }\end{array}$ & Pre & $\begin{array}{l}73.4 \\
(13.0)\end{array}$ & $\begin{array}{l}51.6 \\
(26.8)\end{array}$ & $\begin{array}{l}65.2 \\
(9.2)\end{array}$ & .199 & 57.1 & 89.6 \\
\hline & Post & $\begin{array}{r}56.0 \\
(3.4)\end{array}$ & $\begin{array}{r}44.4 \\
(7.8)\end{array}$ & $\begin{array}{r}51.6 \\
(4.8)\end{array}$ & $.02 * *$ & 46.6 & 54.6 \\
\hline $\begin{array}{l}\text { Social } \\
\text { Phobia }\end{array}$ & Pre & $\begin{array}{l}59.2 \\
(17.2)\end{array}$ & $\begin{array}{l}60.6 \\
(27.1)\end{array}$ & $\begin{array}{l}57.2 \\
(11.6)\end{array}$ & .96 & 48.8 & 69.1 \\
\hline & Post & $\begin{array}{l}50.47 \\
(20.4)\end{array}$ & $\begin{array}{l}50.8 \\
(7.5)\end{array}$ & $\begin{array}{r}45.2 \\
(3.9)\end{array}$ & .47 & 43.5 & 57.4 \\
\hline $\begin{array}{l}\text { Separation } \\
\text { Anxiety }\end{array}$ & Pre & $\begin{array}{c}90.2 \\
(23.9)\end{array}$ & $\begin{array}{c}58.2 \\
(27.3)\end{array}$ & $\begin{array}{l}75.6 \\
(15.46)\end{array}$ & .12 & 60.7 & 88.5 \\
\hline & Post & $\begin{array}{l}77.2 \\
(19.6)\end{array}$ & $\begin{array}{r}54.4 \\
(7.6)\end{array}$ & $\begin{array}{l}60.2 \\
(9.52)\end{array}$ & .49 & 55.1 & 72.75 \\
\hline $\begin{array}{l}\text { Obsessive } \\
\text { Compulsive }\end{array}$ & Pre & $\begin{array}{c}93.4 \\
(21.3)\end{array}$ & $\begin{array}{c}53.2 \\
(23.6)\end{array}$ & $\begin{array}{l}67.60 \\
(17.72)\end{array}$ & $.03 *$ & 57.0 & 85.79 \\
\hline & Post & $\begin{array}{l}71.4 \\
(16.4)\end{array}$ & $\begin{array}{c}63.4 \\
(12.3)\end{array}$ & $\begin{array}{c}63.4 \\
(8.25)\end{array}$ & .51 & 58.9 & 72.81 \\
\hline Depression & Pre & $\begin{array}{c}78.0 \\
(10.4)\end{array}$ & $\begin{array}{l}59.2 \\
(30.0)\end{array}$ & $\begin{array}{l}93.0 \\
(18.92)\end{array}$ & .80 & 63.2 & 90.26 \\
\hline & Post & $\begin{array}{c}62.2 \\
(20.6)\end{array}$ & $\begin{array}{r}49.0 \\
(7.4)\end{array}$ & $\begin{array}{l}70.40 \\
(14.22)\end{array}$ & .11 & 51.2 & 69.78 \\
\hline
\end{tabular}

of 70 and above. Results shown in the carer and self-reported t-scores above indicates meaningful improvements in the anxiety and depression t-scores of the participants at time 2 .

Further analysis revealed that the groups differed significantly in Generalised Anxiety scores, $F(2,12)=5.82, p=.017$ and Social Phobia scores, $F(2,12)=8.02, p=.006$, at pre-test 
Journal of Symbols \& Sandplay Therapy, Vol.12 No.1.

Table 8. RCADS: Carer reports total pre and post anxiety and depression scores $(\mathrm{N}=15)$

\begin{tabular}{lccc}
\hline Item & & Score M(SD) & $t$ \\
\hline $\begin{array}{l}\text { Total Anxiety } \\
\begin{array}{l}\text { Depression } \\
\text { Scores }\end{array}\end{array}$ & Pre & $90.86(12.06)$ & $11.40^{*}$ \\
& & & \\
& Post & $66.86(11.46)$ & \\
\hline$* p<001$ & &
\end{tabular}
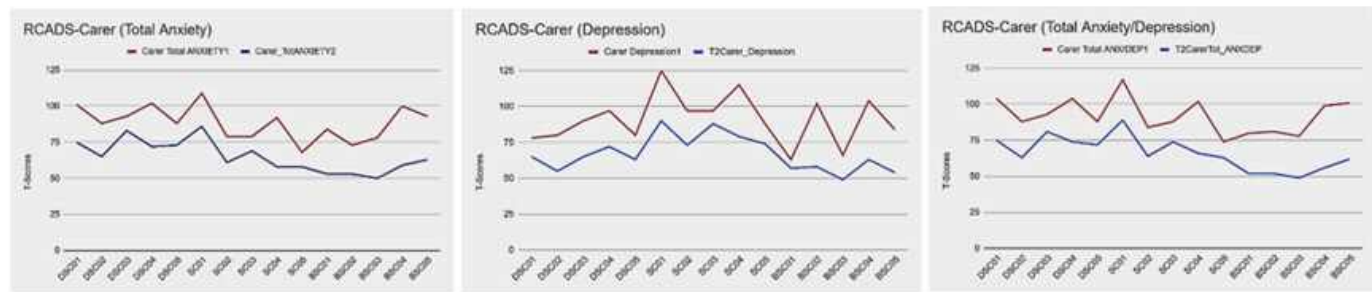

Figure 4a. RCADS-Carer T-Scores on Children's anxiety and depression levels
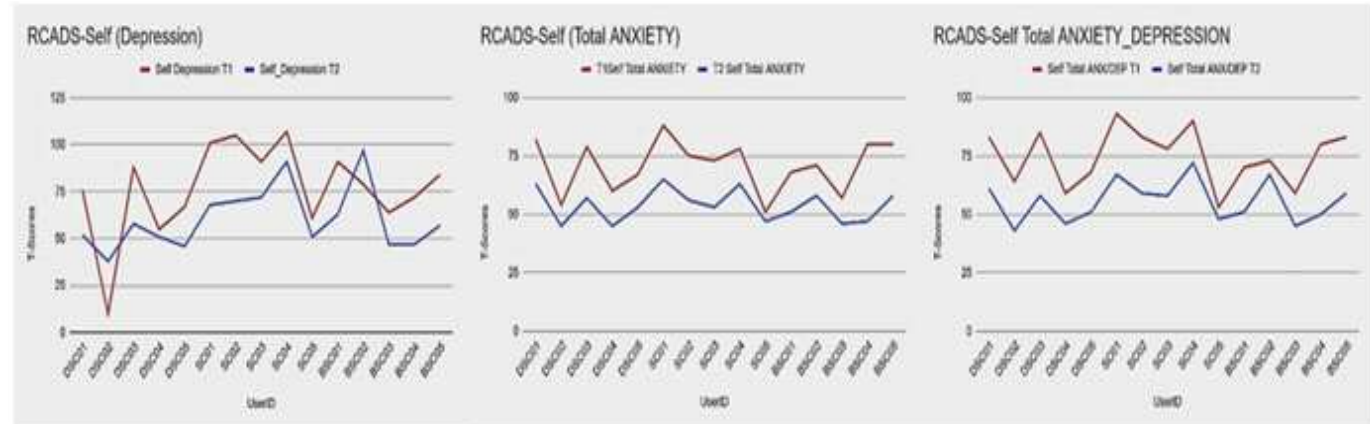

Figure 4b. RCADS-Self reported T-Scores on Children's anxiety and depression levels

respectively. A significant decrease in post-intervention Anxiety scores across the three groups was observed, $F(2,12)=69.97, p=.017$. Total Internalising scores decreased significantly between the groups at post time point, $F(2,12)=538.07, p=.005$. Further, a significant decrease in depression scores was observed at post time point, $F(2,12)=18.90, p=.000$. Together this suggests that the sand play intervention reduced observed anxiety and internalising symptoms among the children. RCADS Carer data for the three groups appear in Table 7. 
Post hoc comparisons using the Tukey hsd test indicated that boarding school children ( $\mathrm{M}=$ 69.0, $\mathrm{SD}=6.5)$ differed significantly from street children $(\mathrm{M}=85.0, \mathrm{SD}=9.5)$ in generalised anxiety scores pre-intervention. Suggesting street children had higher baseline generalised anxiety symptoms when compared to boarding school children. Similarly, social phobia scores between street children $(\mathrm{M}=48.8, \mathrm{SD}=8.1)$ and day school children $(\mathrm{M}=$ 87.0, SD = 3.3) differed significantly pre-intervention, indicating that day school children presented with higher social phobia than street children. Post-intervention, this trend continued between day school and street children.

Depression scoring post-invention revealed day children $(\mathrm{M}=64.0, \mathrm{SD}=6.1)$ differed significantly from street children $(\mathrm{M}=80.0, \mathrm{SD}=7.8)$. Total anxiety scores post intervention revealed significant differences between day school children $(\mathrm{M}=73.6, \mathrm{SD}=6.8)$ and boarding school children $(\mathrm{M}=85.6, \mathrm{SD}=11.0)$. Boarding school children $(\mathrm{M}=54.2, \mathrm{SD}=5.0)$ showed the greatest reduction total internalising scores post intervention when compared to street children $(\mathrm{M}=71.2, \mathrm{SD}=10.8)$ and day school children $(\mathrm{M}=73.0, \mathrm{SD}=6.5)$ suggesting that group sand play therapy showed the greatest effect in reducing internalising symptoms for the boarding school children.

\section{Discussion}

The present study aimed to examine the impact of a nine-week sandplay intervention on participants' prosocial behaviour, resilience, and positive peer relationships through analysis of the SDQ. In addition, the authors aimed to examine a decrease in anxiety/depression symptoms through analysis of the RCADS. Our findings showed that brief SPT has a positive bearing on some aspects of psychological and behavioural outcomes for the street children involved in this study. The results suggest that the use of a group sandplay intervention with children linked to an Orphanage in Uganda led to a change in the participants, significantly impacting the children's conduct problems, total difficulty scores, generalised anxiety and social phobia scores. There was also an improvement in the children's prosocial scores after the intervention. This result is in line with the results shown by Jang (2012), in which there was a reduction in participants' anxiety due to the social interactions which took place during the SPT process. 
Journal of Symbols \& Sandplay Therapy, Vol.12 No.1.

The results of the current study showed that participants experienced a reduction in social phobia, which correlates to the results shown by Jang (2012) and Kalff (1991), whereby a reduction in loneliness was named as a direct result of the use of SPT due to the support and sympathy received during the sandplay therapy. These findings also correspond with the findings of Maeng and Jang (2014) who reported an increase in sociality and decrease in anxiety in the experimental group compared to no change in the control group of college students with blindness. Together with the previous research, these results may show the impact of a group intervention as group intervention enables the introduction of focused interactions with others. Our findings indicating that group interaction and teamwork among street children especially in enjoyable activities can positively influence their fear of social interaction.

Corroborating with Myburgh et al. (2015) findings, street children presented with higher baseline generalised anxiety scores. An overall decrease in total anxiety and depression was observed in both carer and self-reported RCADS confirming similar results outlined by Baggerly and Parker (2005) and Bratton and Ray (2002) respectively. The present study showed that group SPT significantly reduced the children's internalising and externalising symptomatology, affirming Jang's (2012) findings. A decrease in conduct problems was observed post-intervention echoing Kalffs (1991) research that group SPT is an effective strategy to reduce delinquency and aggressive behaviours in children. The use of SPT as intervention for psychological and behavioural difficulties in street children may be effective in reducing referrals for worsening psychopathologies and enable healing among traumatized street children.

It is essential to be aware that the term "boarding school" refers to children sent to monitored and secured schools after leaving the streets. Many of these children have faced and still face significant deprivation and hardship. Their lives likely have more in common with the street children group than the day school children. Vulnerable and already wounded street children who attends boarding school may become easy target for teasing and bullying, this can also become a very lonely place and a torture for these children as they have no recourse to emotional support, guidance, and consolation from Caregivers. An account of a female Ugandan who emigrated to Ireland illustrated the "tough disciplinary measures when a student misbehaves. Besides corporal punishment, children are given the punishment of cleaning the whole floor of a building and kneeling on the floor for several hours" (Irish Times, 2018). Consistent with that is the expression of the theme of security-danger which occurs eight times 
in the sandplay of the street children and 11 times in that of the boarding school children, while it occurred just three times in that of the day school children who are more privileged with caregivers support and motivation. This may be interpreted as reflective of the experiences these children have faced in their past and present.

Some results may be contrary to expectations. In particular, the theme of recreation occurred 19 times in the sandplay of the street children group, while it occurred just eight times overall for each of the other two groups. Even though the streets are perceived as a challenging place to live in, these associated challenges and dangers may be compromised for the benefits encountered on the streets that are sustenance, social gathering, adventure, fun, freedom, and economic provenance. As many of the sand play creations deal with the future, this may also be aspirational. These children's circumstances may give them further impetus to project a better lifestyle onto their future whereby a striving for autonomy is depicted in their sand play creations. In a somewhat similar vein, the theme of basic needs was expressed least by the street children group, with just eight instances, and was expressed by the day school children and boarding school children 10 and 17 times, respectively. It may be speculated that the street children may take the ongoing struggle to meet these needs for granted.

In contrast, the boarding school group has some distance from the issue given that they can compare their experience at school to their experiences before that in the streets. Alternatively, street children, who are used to begging, petty theft and scavenging food in the dumpsters, may have improvised access to nutrition and food variability than those who rely on the provision of food by an institution, such as a boarding school. This view is also supported due to boarding school children expressing security and danger themes more than any other group. This result links to the data presented by UNICEF (2015), whereby $75 \%$ of children in Uganda were a victim of at least one form of violence during their childhood years.

During this process, the emergent theme groupings were noted to bear a strong resemblance to the categories present in Maslow's Hierarchy of Needs (Nasir, Khalid \& Shoukat, 2014; Maslow, 1943). The theme of basic needs mirrors that of physiological needs, to the point of being virtually synonymous. Similarly, the security-danger theme group strongly mirrors that of safety needs. Community-love-celebration coheres with Maslow's love and belonging, while seeking help-faith is somewhat ambiguous, relating to both basic needs, as the children often mentioned faith in the context of seeking help from the divine, as well as the love and 
Journal of Symbols \& Sandplay Therapy, Vol.12 No.1.

belonging category. This may emerge as an adaptive, resilient response to the struggles and psychological impact of their trauma and deprivation. It is almost therapeutic to hand over their challenges to the 'Other' in peak experiences that are mystical and spiritual. The children are unconsciously reliant on the support and ability for this "help" that often comes to their developmental aid in order to find some meaning and purpose in their survival journey.

The giving help-leadership-empowerment theme could be said to relate both to Esteem Needs as well as self-actualisation. Similarly, both education and recreation-self-developmentself-nurturance are somewhat ambiguous; while the present researchers contend that these may relate to self-actualisation, Maslow places recreation and enjoyment in the love and belonging category. Education has been linked here to self-actualisation, the highest level of Maslow's hierarchy, though he originally placed it among safety needs. It is speculated that despite education being a fundamental human right, in the cultural and circumstantial context of these children, it represents an aspiration linked with a better future rather than something that can be taken as a given.

\section{Limitations}

The present study has a range of limitations. The sample size is small, and given the quasi-observational nature of this study, sub-groups are not ideally matched. Similarly, since the researchers were dependent on project workers to conduct the SPT and the psychometric assessments, there was no direct control over how they were administered. The intervention was delivered to Ugandan children by Ugandan project workers and analysed by European researchers. Therefore, there is a possible influence of cultural differences and biases with the initial coding process.

The study only utilised forty-five minutes of group therapy session per week for nine weeks in a brief SPT research design; suggestions of an increased frequency of intervention possibly twice or three times weekly over a longer time period could have improved the chances of a more significant result. In addition to this, the study observations were based on pre-existing conditions i.e. participants and the groups chosen, therefore there is an issue of potential selection bias in the recruitment of our sample and similarly having 'no control' in the study 
may create a challenge for the reader in determining the possible impact of extraneous variables in the outcomes of the study.

More so, the self-reported SDQ's were administered to participants age 11-17 $(\mathrm{n}=6)$, they were not completed accurately, researchers observed $79 \%$ missing data in the variable scoring leading to missing total scores and a difficulty with imputation. Considering our sample size and variables is relatively small, these missing data means a loss of valuable information which may cause an imbalance and invalid inference, a significant bias and was therefore omitted from our analysis. As a result, the SDQ analysis presented the Carer's reported perspectives.

Although, the project workers received a brief course in sandplay delivered by a Child and Adult Jungian Analyst and cannot be considered professionally skilled in this method. Due to the project workers possibly suggesting themes to the participants during some sandplay trays, this may have caused some bias and such bias may have implications for our findings.

\section{Conclusion}

An insight is provided into the vulnerability and resilience in street children alongside the rehabilitation and reintegration into normalcy in their community. This research initiates the dire demand and necessity of providing recourse for the developing child's psychological needs. These needs were presented as intrapersonal as well as interpersonal dimensions.

This study supports the idea that sandplay can be utilised to improve children's psychological health, specifically conduct disorder, social phobia, generalised anxiety, and depression. The data may also help to provide a clearer understanding of the impact that a brief SPT group intervention can have on individuals, however, overall this should be treated as a pilot study, with future work delving more deeply into the questions and limitations raised here. More specifically, future research should endeavour to conclusively ascertain what types of group therapies work best for these types of low-resource environments, focusing on how best to train project workers, teachers, and caregivers to administer these interventions effectively. 
Journal of Symbols \& Sandplay Therapy, Vol.12 No.1.

\section{References}

American Psychiatric Association. (2000). Diagnostic and statistical manual of mental disorders (4 ${ }^{\text {th }}$ ed.). American Psychiatric Association.

Baggerly, J., \& Parker, M. (2005). Child-centred group play therapy with African American boys of the elementary school level. Journal of Counselling \& Development, 83, 387-396.

Bayat, A. (2000). From 'dangerous classes' to 'quiet rebels': politics of the urban subaltern in the Global South. International Sociology, 15, 533-557.

Becker, S. P., Schindler, D. N., Holdaway, A. S., Tamm, L., Epstein, J. N., \& Luebbe, A. M. (2019). The Revised Child Anxiety and Depression Scales (RCADS): Psychometric Evaluation in Children Evaluated for ADHD. Journal of Psychopathology and Behavioral Assessment, 41(1), 93-106. doi.org/10.1007/s10862-018-9702-6

Braun, V., \& Clarke, V. (2006). Using thematic analysis in psychology. Qualitative research in psychology, 3(2), 77-101.

Bratton, S., Ray, D., Rhine, T., \& Jones, I. (2005). The efficacy of play therapy with children: A meta-analytic review of treatment outcome. Professional Psychology: Research and Practice, 36(4), 376-39.

Briere, J. \& Jordan, C. (2009). Childhood maltreatment, intervening variables, and adult psychological difficulties in women. Trauma, Violence, \& Abuse, 10(4), 375-388.

Campbell, M. (2004). Value of sandplay as a therapeutic tool for school guidance counsellors. Australian Journal of Guidance and Counselling, 14(2), 211-232.

Chorpita, B. F., Yim, L. M., Moffitt, C. E., Umemoto L. A., \& Francis, S. E. (2000). Assessment of symptoms of DSM-IV anxiety and depression in children: A Revised Child Anxiety and Depression Scale. Behaviour Research and Therapy, 38, 835-855.

Connolly M., (2004). Child and Family Welfare: Statutory response to children at risk. Te Awatea Press.

Carey, L. (1990). Sandplay therapy with a troubled child. The Arts in Psychotherapy, 17(3), 197-209.

Corey, M. S., \& Corey, G. (2006). Groups: process and practice. Thomson Learning Inc.

Dye, H. (2018). The impact and long-term effects of childhood trauma. Journal of Human Behavior in the Social Environment, 28(3), 381-392.

Edwards, V., Holden, G., Felitti, V., \& Anda, R. (2003). Relationship between multiple forms of childhood maltreatment and adult mental health in community respondents: Results from the 
adverse childhood experiences study. The American Journal of Psychiatry, 1608), 1453-1460.

Embleton, L., Lee, H., Gunn, J., Ayuku, D., \& Braitstein, P. (2016). Causes of child and youth homelessness in developed and developing countries: a systematic review and meta-analysis. JAMA pediatrics, 1705), 435-444.

Gallo-Lopez, L., Schaefer, C. E., Milgrom, C., Kestly, T., Munns, E., Brown, C. J., ․ Riviere, S. (2010). Play Therapy with Adolescents. Jason Aronson, Incorporated. https://books.google.ie/books?id=Lt19qRw2k8cC.

Garg, P. S. (2004). Street Children: Lives of Valor \& Vulnerability. Reference Press.

Glaser, D. (2000). Child abuse and neglect and the brain-a review. Journal of child psychology and psychiatry, 41(1), 97-116.

Goodman, R. (2001). Psychometric properties of the strengths and difficulties questionnaire. Journal of the American Academy of Child and Adolescent Psychiatry, 4011), 1337-1345.

Greenwood, R. M, Stefancic A,. \& Tsemberis S. (2013). Pathways housing first for homeless persons with psychiatric disabilities: Program innovation, research, and advocacy. Journal of Social Issues, 69 (4), 645-663.

Grubbs, G. G. (2005). The Sandplay Categorical Checklist for Sandplay Analysis. Rubedo Publishing.

Harper, C., \& Marcus, R. (2000). Child poverty in Sub-Saharan Africa. unpublished report, Save the Children UK.

Henwood, B. F., Derejko, K. S., Couture, J., \& Padgett, D. K. (2015). Maslow and mental health recovery: a comparative study of homeless programs for adults with serious mental illness. Administration and policy in mental health, 42(2), 220-228. doi:10.1007/s10488-014-0542-8

Homeyer, L. E., \& Sweeney, D. S. (2017). Sandtray Therapy (3rd ed.). Routledge.

Human Rights Watch (2014). "Where do you want us to go?" Abuses against Street Children in Uganda. retrieved from https://www.hrw.org/report/2014/07/17/where-do-you-want-us-go/abuses-against-street-children-ugand a

Human Rights Watch (2014). Uganda: Homeless Children face Violence, Exploitation. End Roundups, detention with Adults.

https:/www.hrw.org/news/2014/07/16/uganda-homeless-children-face-violence-exploitation.

International Labour Organization (2013). Uganda National Child Labour Survey Report 2011-2012:

National Labour Force and Child Activities Survey 2011-2012.

http://www.ilo.org/ipecinfo/product/download.do?type=document\&id $=26415$

International Labour Organization (2018). Uganda National Labour Force Survey Report 2016-2017. 
Journal of Symbols \& Sandplay Therapy, Vol.12 No.1.

Uganda Bureau of Statistics. Kampala.

https://www.ilo.org/surveyLib/index.php/catalog/2976/download/20996

Isom, E. E., Groves-Radomski, J., \& McConaha, M. M. (2015). Sandtray Therapy: A Familial Approach to Healing Through Imagination. Journal of Creativity in Mental Health, 1033), 339-350. Jang, M., \& Kim, Y. (2012). The effect of group sandplay therapy on the social anxiety, loneliness and self-expression of migrant women in international marriages in South Korea. The Arts in Psychotherapy, 39(1), 38-41.

Jang, M. (2009). Child counselling. Tae-Young Publishing Company

Kalff, D. M. (1989). The sandplay. A contribution from CG Jung's Point of view on child therapy. Journal of Sandplay Therapy, 16(2), 49-72.

Kalff, D. (1991) Introduction to Sandplay Therapy. Journal of Sandplay Therapy, 1(1), 9-15.

Kestly, T. (2010). Group sandplay in elementary schools. In A. A. Drewes \& C. E. Schaefer (Eds.), School-based play therapy (p. 257-281). John Wiley \& Sons Inc.

Lowenfeld, M. (1939). The world pictures of children: A method of recording and studying them. The Journal of Psychology, 30, 325-331. doi:10.1111j.2044-8341.1939.tb00710.

Lowenfeld, M. (1997). Understanding Children's Sandplay. Lowenfeld World Technique. Allen and Unwin.

Lundh, L.G., Wangby-Lundh, M., \& Bjarehed, J. (2008). Self-reported emotional and behavioural problems in Swedish 14 to 15-year-old adolescents: A study with the self-report version of the Strengths and Difficulties Questionnaire. Scandinavian Journal of Psychology, 49, 523-532.

Lyles, M., \& Homeyer, L. E. (2015). The Use of Sandtray Therapy with Adoptive Families. Adoption Quarterly, 18(1), 67-80.

Maslow, A. H. (1943). A theory of human motivation. Psychological Review, 504), 370-96.

Maeng, J., \& Jang, M. (2014). The Effects of Sandplay Therapy on the Anxiety, Self-esteem, and Sociality of College Students with Blindness. Journal of Symbols \& Sandplay Therapy, 5(1), 14-22.

McCormick, R., Rosenblad, S. R, \& Newmeyer, M. (2020). Untapped Therapeutic Potential: Using Sandtray in Substance Abuse Treatment Groups. Journal of Creativity in Mental Health, https://doi.org/10.1080/15401383.2020.1789016

Meacham, F., \& Bergstrom, T. C. (2016). Adaptive behaviour can produce maladaptive anxiety due to individual differences in experience. Evolution, medicine, and public health, 2016(1), 270-285. https://doi.org/10.1093/emph/eow024

Meyer, J. C. (1997). "Personology: From Individual to Ecosystem”. CTP Book Printers.

Mieloo, C., Raat, H., van Oort, F., Bevaart, F., Vogel, I., Donker, M., \& Jansen, W. (2012). 
Validity and reliability of the strengths and difficulties questionnaire in 5-6-year olds: Differences by gender or parental education. PLoS One, 7(5), 1-8.

Mitchell, R. R., \& Friedman, H. S. (1994). Sandplay: Past, present, and future. Psychology Press.

Munene, J., \& Nambi, J. (1996). Understanding and helping street children in Uganda. Community Development Journal, 31(4), 343-350.

Muris, P., Meesters, C., \& Van den Berg, F. (2003). The Strengths and Difficulties Questionnaire (SDQ): Further evidence for its reliability and validity in a community sample of Dutch children and adolescents. European Child and Adolescent Psychiatry, 12(1), 1-8.

Myburgh, C., Moolla, A., \& Poggenpoel, M. (2015). The lived experiences of children living on the streets of Hillbrow, Curationis 38(1).

Nasab, H. M., \& Alipour, Z. M. (2015). The effectiveness of Sandplay Therapy in reducing symptoms of separation anxiety in children 5 to 7 years old. Journal of Educational Sciences \& Psychology, 5(1).

Nasir, M., Khalid, A., \& Shoukat, A. (2014). Maslow theory of human development and emergence of street children phenomenon in Pakistan. Pakistan Vision, 15(2), 98.

New Vision (Uganda). (2001). Government to study street children. Pitman.

Pollak, S. (2018). 'My grandmother sent me to boarding school to protect me. It was a much safer option'. Irish Times.

https://www.irishtimes.com/life-and-style/people/my-grandmother-sent-me-to-boarding-school-to-protec t-me-it-was-a-much-safer-option-1.3592255

Punnett, A. \& Canfield, M. (2020). Changes in verbalizations during sandplay: An empirical study. Journal of Analytical Psychology, 65(3), 497-518.

Ramos, D. G., \& de Matta, R. M. (2008). Sandplay. A method for data analysis. Journal of Sandplay Therapy, 17(2), 93-115.

Reber Arthur S. (1985). The Penguin Dictionary of Psychology. Penguin Group.

Ramsey, L. C. (2014). Windows and bridges of sand: Cross-cultural counseling using sand tray methods. Procedia - Social and Behavioral Sciences, 159, 541-545.

https://doi.org/10.1016/j.sbspro.2014.12.421

Roesler, C. (2019). Sandplay therapy: An overview of theory, applications and evidence base. The Arts in Psychotherapy, 64, 84-94.

Roncević, N., Stojadinović, A., \& Batrnekantonić, D. (2013). Street children. Srpski arhiv za celokupno lekarstvo, 141(11-12), 835-841.

Sangganjanavanich, V. F., \& Magnuson, S. (2011). Using sand trays and miniature figures to 
Journal of Symbols \& Sandplay Therapy, Vol.12 No.1.

facilitate career decision making. The Career Development Quarterly, 593), 264-273.

UNESCO (2017) Estimation of the numbers and rates of out-of-school children and adolescents using administrative and household survey data. UNESCO Institute for Statistics. Montreal UIS/2017/ED/TD/4. Retrieved from https://doi.org/10.15220/978-92-9189-207-5-en

UNICEF (2015). Ministry of Gender, Labour and Social Development. Violence against Children in Uganda: Findings from a National Survey. Kampala, Uganda.

https://www.unicef.org/uganda/media/2156/file/Violence\%20Against\%20Children\%20Survey\%202018. pdf

Van Blerk, L. (2003). The 'place' of street children in Kampala, Uganda: marginalisation, resistance, and acceptance in the urban environment. Environment and planning D: Society and Space, 21(5), 607-627.

Walakira, E. J., Ddumba-Nyanzi, I., Lishan, S., \& Baizerman, M. (2014). No place is safe: violence against and among children and youth in street situations in Uganda. Vulnerable Children and Youth Studies, 94), 332-340. doi:10.1080/17450128.2014.934750

Weinrib, E. (1983). Images of the self: the sandplay therapy process. Sligo Press

Winnicott, D. W., (1971). Playing and Reality. Tavistock Publications.

World Bank. (2013). Africa Development Indicators 2012/2013. The World Bank.

http://data.worldbank.org/http://hdr.undp.org/en/content/population-living-below-125-ppp-day

World Health Organisation (WHO). (2014). Mental Health Atlas. World Health Organisation.

Yao, S., Zhang, C., Zhu, X., Jing, X., McWhinnie, C. M., \& Abela, J. R. Z. (2009). Measuring Adolescent Psychopathology: Psychometric Properties of the Self-Report Strengths and Difficulties Questionnaire in a sample of Chinese adolescents. Journal of Adolescent Health, 45, 55-62. 